\title{
Outdoor earthen plasters
}

DOI 10.5592/otmcj.2012.1.7 Research paper

\author{
Pavel Svoboda \\ doc. Ing., CSc, Praha, Czech Republic \\ e-mail: svobodap@fsv.cvut.cz
}

\author{
Michal Procházka \\ Ing., Třebíč, Czech Republic \\ e-mail: hrochi@post.cz
}

CONSTRUCTION OF ECOLOGICAL BUILDINGS HAS ONE SPECIFIC SUB-SEGMENT - CONSTRUCTION WITH NATURAL MATERIALS. These are buildings made of timber, earth, stone, straw bales, reed, hemp, etc. The majority of these materials need protection against external effects. Architectural or structural elements (roofing overlaps etc.) provide passive protection. Outdoor plasters may be used as an active protection element.

The practice to-date has mostly applied lime plasters with high demands for treatment during the first two to three months. An alternative choice were unstabilized earthen plasters with high demands for maintenance. The research intention, therefore, was to develop an outdoor plaster based on natural materials resistant to external weather effects.

The desired solution was a plaster of unburnt earth with slightly modified properties, mainly in reaction to water. In the first phase of research, extensive literature search, dozens of potential stabilizing agents were shortlisted. The selection criteria were: water resistance plus low diffusion resistance of the resulting material, improved strength characteristics, a zero effect on colour and appearance etc. Many alternative agents were rejected.

Positive results were reached with special types of polymer binders applied in small doses into earthen plasters. It must be emphasized that it is the plaster quality that plays a significant role here (the analysis would provide a topic for a separate article). The plaster is also suitable for repairs and reconstructions of historical earthen structures.

These plasters are protected by a utility model.

Outdoor earthen plasters were first introduced to the Czech market at the end of 2009.

Keywords

earthen, plasters, outdoor, clay, polymer, stabilize, adobe

\section{Introduction}

Going back to the starting point of the development, the following question arises: What are the desirable parameters of stabilized outdoor earthen plaster? To be able to reply to this question, we must first define onto what surfaces the plaster will be applied.
Modern earthen structures built in our climatic zone must be fitted with thermal insulation and treated as compositions open to diffusion. This results in the second demand - the plaster must possess a low diffusion resistance. The former demand logically implies resistance to the effects of rainwater 
wind-driven under roofing overlaps. Among other important demands we may mention: elasticity, a zero or minimum effect on colour shading and appearance, improved strength characteristics - in tension in particular, and others. These demands are not met by existing stabilizers. Lime and cement form a so-called dual system (different shrinkage of the crystalline grid and clays minerals), which causes brittleness. Silicones and bitumen raise the diffusion resistance, and bitumen also changes color. Gypsum is not sufficiently water resistant, etc. Finally, we cannot ignore the last parameter, i.e. the price, in our considerations. For the price of construction chemicals may substantially exceed the price of e.g. lime and cement, but, on the other hand, more environment friendly dosing may be expected.

\section{Development path}

Following the first year of literature search it has not been found any satisfactory paper. So I began to scan Catalogue of ingredients for concrete, mortars and plasters [1] product by product. During research in the area of alternative stabilization methods of unburnt earth, dozens of selected stabilizers and binders were removed from the list. Such added binders are called stabilizing or secondary binders. Dispersion polymer binders were predominantly shortlisted. The principal reason for this choice was mainly the fact that the binder exerts elastic action and, therefore, will be able to act compositely with clay. The second reason was the fact that these polymers disperse in water, which is a thinning agent for unburnt earth. The final, third reason was the hope for a minimum increase of diffusion resistance of plasters. The result, however, failed to meet all the expectations perfectly. After contact with water, the material did hold together, but its strength had dramatically fallen. The reason for this is straightforward - the material was soaked with water which had caused clay swelling and thus a loss of the primary binder ( clay) function. Therefore, seeking a solution, I turned to hydrophobization. If water does not penetrate into the material, clays do not start to swell. Hydrophobization alone proved problematic and insufficient. The most favourable option, eventually, were special types of polymers. Polymers act both as secondary binders which substitute primary binder in dry state, mainly on the surface, and, at the same time, these polymers in particular are able to ensure protection against water penetration inside the material. This very combination of secondary binder and hydrophobization proved to be of key significance. The polymers shortlisted for this characteristic were investigated for efficiency: the selected one with the highest efficiency will allow minimizing the dosage. With regard to the adequate quality of stabilization, low diffusion resistance, environment friendly approach and the price of the resulting product, the current recommended dosage selected is $0.5 \%$ by weight for coarse plasters and $1 \%$ by weight for fine plasters.

\section{Tests}

Specimens were made from clay and sand $0 / 4$ (sand for mortars). The ratio is determined by the shrinkage. The value of shrinkage must be less than $2 \%$, while the dose of water is based on the real consistence. Consistence is defined by value $175 \mathrm{~mm}$ by slump flow test by ČSN EN 1015-3 [2]. Further tests were carried out:

\begin{tabular}{|c|c|c|}
\hline Test method & Specimen dimensions & Number of specimens \\
\hline Water Vapour Permeability & cylinder $\emptyset_{120} \mathrm{~mm}, \mathrm{~h}=15 \mathrm{~mm}$ & 8 kinds, $3 / 5$ pieces ( 26 total) \\
\hline Tensile Bending Strength & block $40 \times 40 \times 160 \mathrm{~mm}$ & 8 kinds, 3 pieces (24 total) \\
\hline Compressive Strength & block $40 \times 40 \times \mathrm{ca} 80 \mathrm{~mm}$ & 8 kinds, 6 pieces ( 48 total) \\
\hline Resistance to Water Action & block $40 \times 40 \times 160 \mathrm{~mm}$ & 8 kinds, 6 pieces ( 26 total) \\
\hline Test in the Rainfall Simula & plates $300 \times 3$ & 8 kinds, 1 pieces ( 8 total) \\
\hline
\end{tabular}

Table 1. Testing program
Tested kinds of samples were: the first without stabilization, the second with lime, the third with cement and the others five ones with different polymers.

\section{Result}

The diffusion resistance factor has increased only slightly from the maximum of unstabilized plaster of ca 10 [-] to ca 11 [-] for coarse (stabilization with 0.5 wt\%) and ca 12 [-] for fine plaster (stabiwas performed in accordance with ČSN EN 1015-19 [3]. Fig. 1 shows the samples during the measurement process in a constant climate chambers.

Both the tensile and compressive strength have grown (values differ). The growth in tensile strength values commonly amounts up to $100 \%$, while the growth in compressive strength is around 50\% (stabilization with $1 \mathrm{wt} \%$ ). The measurement was performed in accordance with ČSN EN 1015-11 [4], shown in Fig. 2 (Tensile Bending Strength test).

The resistance to water is incomparably higher. It was tested using the modified traditional test according to Havlíček and Souček - the test of resistance to water action [5] which consists in soaking parts of hanging prisms in water for a time period of one hour. The prism dimensions were adapted to $40 \times 40 \times 160$ $\mathrm{mm}$, and water temperature was specified at $20^{\circ} \mathrm{C}$ because inconstancy affects the results. This test we can see on Fig. 3, where is tested stabilization on commercial earthen plasters. lization with $1 \mathrm{wt} \%)$. The measurement 


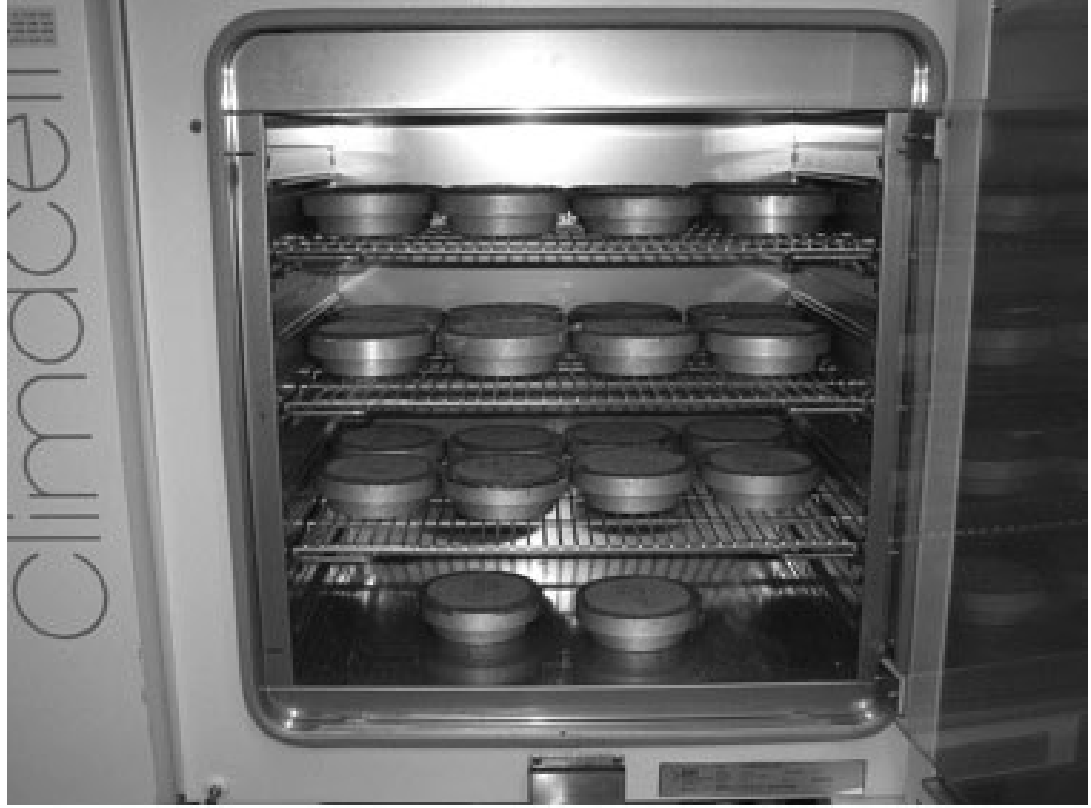

Figure 1. Test pursuant to ČSN EN 1015-19
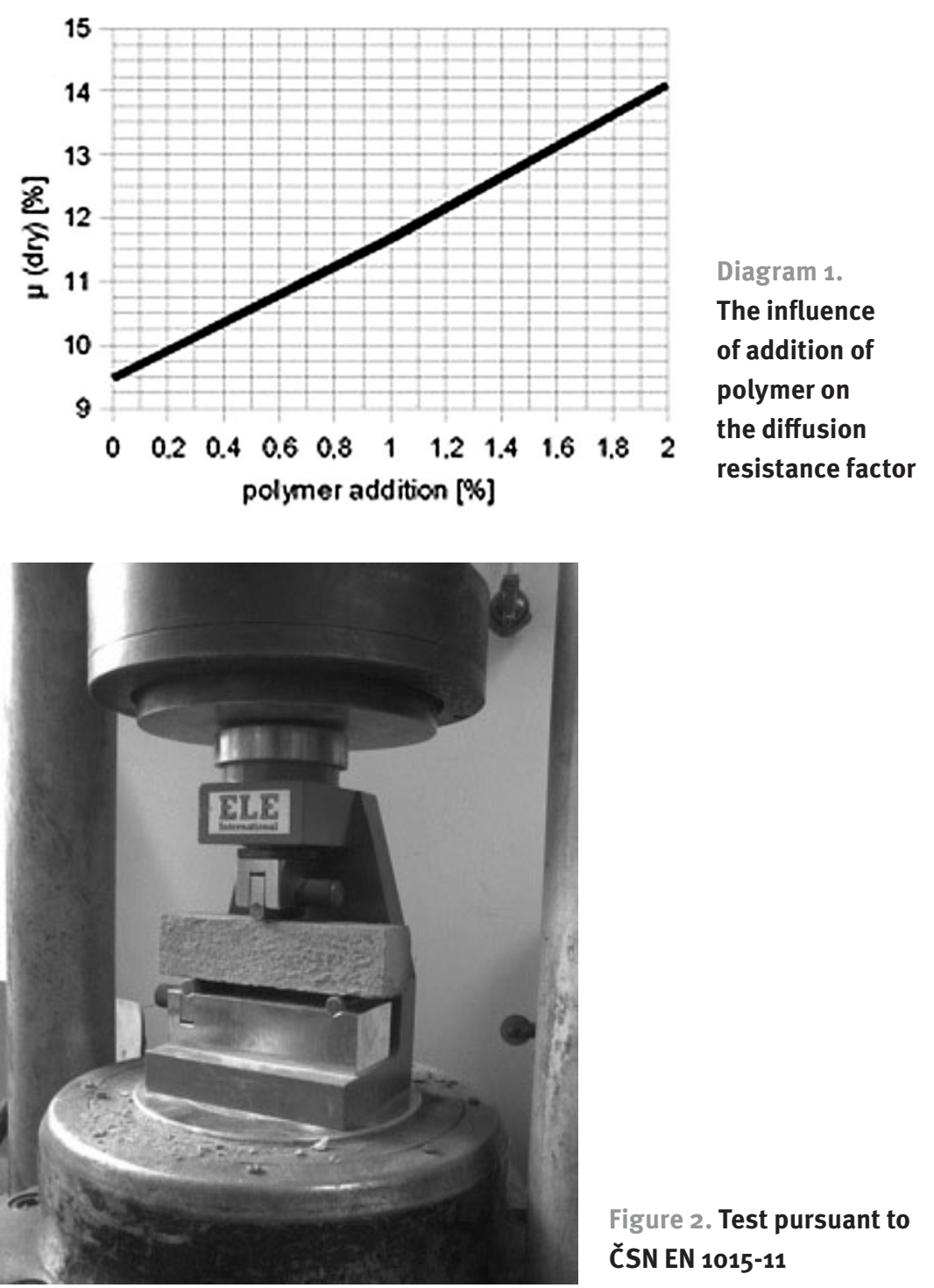

Figure 2. Test pursuant to ČSN EN 1015-11
Other specimens were further exposed to simulated rain in the rainfall simulator to measure erosion. Rainfall simulator is shown in Fig. 4. The rain was selected to last $60 \mathrm{~min}$. with an intensity of $20 \mathrm{~mm} / \mathrm{h}$, followed by a $30 \mathrm{~min}$. break; then there were three torrential rain showers of $15 \mathrm{~min}$. with an intensity of $60 \mathrm{~mm} / \mathrm{h}$ with 5-minute breaks.

The following illustration in Fig. 5 displays the differences between the stabilizer dosing after simulated rain. The specimen stabilized with $1 \mathrm{wt} \%$ of polymer does not show any changes, while the specimen stabilized with $0.1 \mathrm{wt} \%$ of polymer shows only slight damage; the specimen without stabilization had completely failed. The dose of $0.1 \mathrm{wt} \%$ is only for illustration. From practice we may say that it is comparable with the best natural stabilizers (cow manure etc.) dosed at values of 10 to $20 \%$ by weight.

\section{Recommendations}

The above-mentioned dosing of stabilizing disperse polymer binders is based on the assumption of observing the structural principles for houses made of natural materials, such as earth, timber, straw bales, reed, hemp and others. The technology of these houses, for example, does not allow non-observance of roofing overlaps, construction of ledges, the absence of a socle, the action of splashing water, a combination of water and frost action, thawing snow and related long-term soaking etc. Unfortunately, postmodern architecture indulges in such approaches, relying on artificial materials resistant to these effects. Outdoor earthen plaster is resistant even to repetitive rainfall. It is, however, suitable if it may dry up after each rain shower. Water in itself does not harm the plaster, but the combination of soaked masonry and frost may slightly reduce its life cycle. It is, in particular, both active 


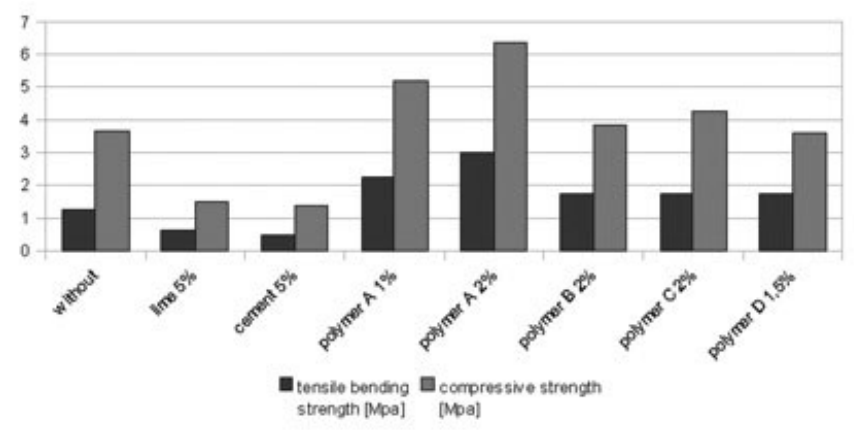

Diagram 2. Influence of kind of stabilization on strength
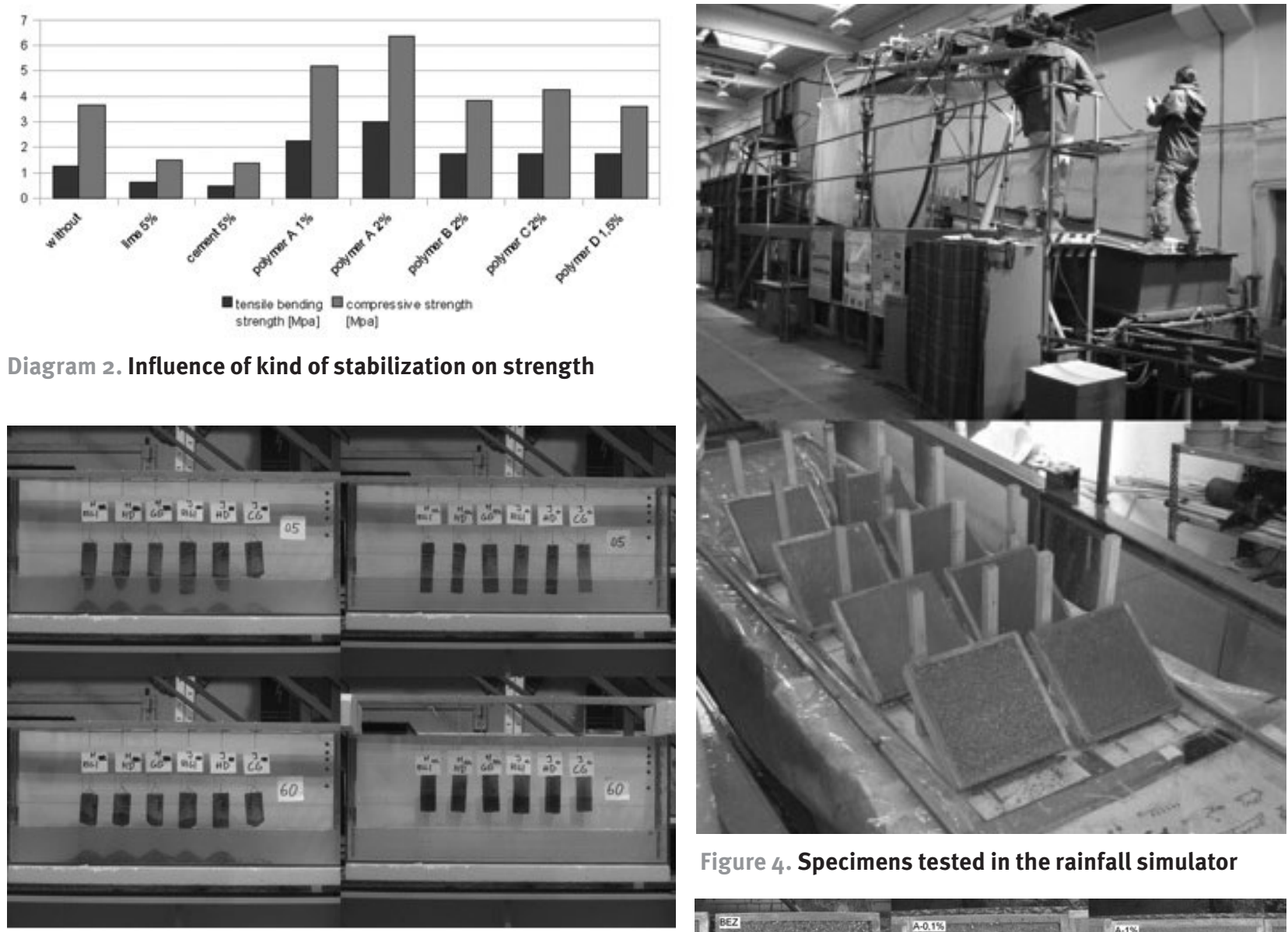

Figure 4. Specimens tested in the rainfall simulator

Figure 3. Test of resistance to water action according to Havliček and Souček; the upper pictures visualize samples after 5 minutes, the lower ones after 60 minutes; the left side is without stabilization, while the right side was stabilized ( $0.5 \mathrm{wt} \%$ and $1 \mathrm{wt} \%$ ).

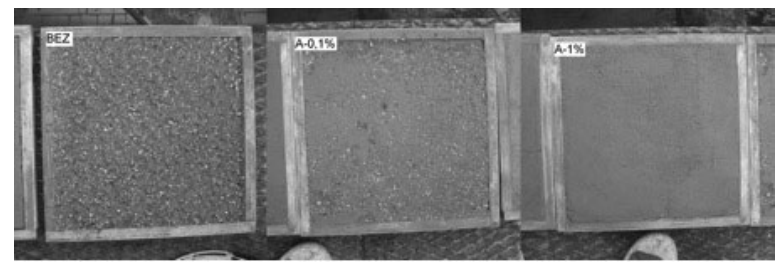

Figure 5. Specimens after testing in the rainfall simulator

and passive masonry protection that will guarantee its long-term life with no necessity for costly maintenance.

Therefore, several recommended compositions and structural details have been designed. These compositions are characterized by sufficient volumes of thermal and moisture accumulation material of unburnt earth on the interior side; a vapour retarder for the moisture flow regulation through the wall and perfect air tightness in the middle of the wall; with massive insulation of straw bales or hemp on the exterior, plus the external "goretex jacket" of outdoor earthen plaster. Exposed parts of buildings may be protected by more strongly stabilized unburnt earth.

\section{Conclusion}

The outdoor earthen plaster stabilized with polymers represents a modern solution to ecological houses of natural materials without any necessity for additional costs for frequent maintenance. At the same time, it represents a perfect solution for reconstructions of historical buildings of unburnt earth.

\section{References}

[1] Catalogue of ingredients for concrete, mortars and plasters for 2004-2006 (2004), Vol. 1, 1st ed., Katalog přisad do betonů, malt a omítek pro období let 2004-2006, Výzkumný ústav maltovin, Praha, pp. 271-32.
[2] ČSN EN 1015-3 - Testing Methods of Mortars for Masonry - Part 19: Determination of consistence of fresh mortar (by flow table).

[3] ČSN EN 1015-19 - Testing Methods of Mortars for Masonry - Part 19: Determination of Water Vapour Permeability through Hardened Mortars for Interior and Exterior Plasters.

[4] ČSN EN 1015-11 - Testing Methods of Mortars for Masonry - Part 11: Determination of Tensile Bending and Compressive Strength of Hardened Mortars.

[5] Havlíček, V. - Souček, K. (1958), Buildings of Unburnt Earth, Státní zemědělské nakladatelství Praha. 